\title{
Approaches and Countermeasures of Developing Low Carbon Economy for the Twelfth Five-Year Plan of Ningxia Hui Autonomous Region
}

\author{
Song Xinxin \\ School of Business \\ Northern University for Nationalities \\ Yinchuan city, Ningxia province, China \\ songxix@163.com
}

\author{
Liu Ting \\ School of Economics \\ Northern University for Nationalities \\ Yinchuan city, Ningxia province, China \\ lemoncowtree@163.com
}

\begin{abstract}
The mode of developing Low carbon economy is an innovation, which indicates the adjustment and innovation of energy structure, industrial structure and technology. It is also a common way of pursuing sustainable development around the world. Ethnic people of Ningxia have made great achievements in economic and social development under the leadership of Chinese government these years. The comprehensive strength and abundant natural resources lay a sound foundation for developing low carbon economy of their "Twelfth- Five Year" plan .In this paper, we analyze the achievements and problem Ningxia Hui Autonomous Region have made and then puts forward the ways and countermeasures of developing low carbon economy for the "Twelfth-Five Year" plan of this area.

Keywords: low carbon economy; approaches;

countermeasures
\end{abstract}

\section{INTRODUCTION}

During the "Eleventh five-year"period, while maintaining stable development in accordance with the the requirements of scientific development, Ningxia province layed great emphasis on conserving resources and protecting environment.We always give priorities to energy-saving, emission reduction and low carbon economy, making great achievement in these areas.

\section{A. Actively Dealing with Climate Change and Attracting the} Attention of the World

During the "Eleventh five-year"period, Ningxia has established management systems and carried out a number of researches to deal with unfavourble climate change, promoting international cooperation and improving peoples'sense of protecting environment by propagation .We have made outstanding achievements in Clean development mechanism (CDM) and gas emission reduction through national cooperation. In view of the great endeavour and achievements of Ningxia in coping with climate change, the featured film "Ningxia of China: actions change our life" has become a highlight in Copenhagen climate conference of Denmark in 2009.

\section{B. Making Great Achievement in Energy-saving and Emission Reduction}

During the "Eleventh five-year"period, Ningxia have made great efforts in energy-saving and emission reduction, accomplishing the mission the State Council assigned . Its energy consumption per unit of GDP has falled from 4.14 tons of standard coal / million yuan in 2005 to 3.308 tons of standard coal / million yuan in 2010 (calculating at comparable price of 2005). Meanwhile, the carbon emissions per unit of GDP also declined significantly, reducing to 10.67 tons of carbon dioxide equivalent / million yuan of 2010 ( calculating at comparable price of 2005) ,approximately $23.51 \%$ lower than the year of 2005 .

\section{C.Strong Momentum of Utilizing New Energy}

During the "Eleventh five-year" period, industrialization and large scale of production make Ningxia's utilization of new energy take on good momentum and its chain of industry is gradually formed. By 2010 , the capacity of grid-connected wind installations of Ningxia province has reached 766,200 kilowatts and solar PV generation has reached 90,330 kilowatts while the popularization rate of solar-energy water heater has reached $20 \%$ (including rural areas) and the ratio of rural solar cooker holders has reached $30 \%$. Besides, we have built many solar photothermal houses with an area of 80,000square metres. In addition, the utilization of rural biogas reached 120,000,000 cubic meters and the rate of biogas households reached $30 \%$. Moreover, we made full use of coal associated resources likelcoal seam gas to a certain scale.

\section{Having Obtained Great Achievement in Protectiong Ecological Environment}

During the "Eleventh-five years" period, Ningxia has carried out key projects as protecting "Three-North Shelterbelts"and natural forests, conversing cropland to forest, returning cropping land to forage land and preventing 
and controling sand.,etc. We planted trees of 5.6 million acres and had new wetland of 0.85 million acres, making the forest coverage increased straightly from $10.5 \%$ in 2005 to $11.4 \%$ in 2010. By doing that, grassland vegetation had been restored, forest and grassland resources have gradually been increased and ecological environment has been obviously improved.

\section{PROBLEMS}

\section{A.Prominent Economic Structural Contradiction}

Having abundant resources, the ratio of high energyconsuming industry in Ningxia' $s$ industrial structure is very large. Coal, electric power, metallurgy and chemical industry have become the strategy-led industry of Ningxia province. In 2010, energy consumption for industry accounted for $84.07 \%$ of the total energy consumption of Ningxia and the comprehensive energy consumption of heavy industry accounted for $93.27 \%$ of total industry energy consumption. The characteristics of single energy and mineral resources and coal-dominated resources of Ningxia province determine that we mainly consume coal with high carbon emissions. Coals accounted for around $85 \%$ in one-off energy consumption .Due to the high carbon emissions in industry and energy, the energy consumption and carbon emission in GDP value of Ningxia is at the top list of China.

\section{B.Growing Energy Consumption and Carbon Emission Results in Low Benifits}

During the "Eleventh five-year" period, the total consumption of primary energy in Ningxia province increased by $45.15 \%$, total consumption of carbon emission increased by $41.74 \%$ and carbon dioxide emissions of energy consumption increased by $41.89 \%$. Therefore, Ningxia is characterised by its "three high, two low"- high consumption of energy, high carbon emission, high pollution, low output and low benefit. In 2010, the unit GDP energy consumption of Ningxia province is 330.8 tons of standard coal / thousand RMB (calculating at a comparable price prices of 2005). Moreover, the unit GDP energy consumption of Ningxia is 3.35 times higher than national average, which ranked first of China. Ningxia's Economic growth is mainly relied on increased consumption of material resources, so the he proportion of enterprises with high consumption of energy and high carbon emission is very large. The industrial energy consumption of Ningxia province accounted for $75 \%$ of energy consumption of China and industries with high consumption of energy occupied $84 \%$ of total industrial energy consumption. The proportion of high energy consumption industries such as electric power, ferroalloy, electrolytic aluminum, coke and calcium carbide is very large, especially industries of iron alloy developed very quickly.

\section{The concept and lifestyle of low-carbon development need further advocating and guiding}

Although the concept of low carbon economy is gradually rooted among people, in the consciousness of many enterprises and general public, there is still certain distance between concept of low-carbon development and life. For many enterprises, they develop low carbon economy just out of business objectives rather than the need of sustainable development. Therefore, there is still a long way to go for public welfare-based development and strategic competitiveness enhancement of enterprises from low carbon economy.

The main energy consumption goes to the secondary industry of Ningxia and the high energy consumption industries take up a large proportion, so the feature of heavy industrialization is very obvious. In order to implement the national strategic deployment and specific tasks in developing low carbon economy, during the period of the

'Twelfth Five-Year Plan', Ningxia Hui Autonomous Region put forward the idea of establishing ecological, green and low-carbon development. We should focus on energy conservation and emission reduction, perfecting the incentive and restraint mechanisms and strengthening the capacity of sustainable development.

\section{COUNTERMEASURES}

\section{A. Speed up Building an Industrial System Characterized by Low Carbon Emissions}

Firstly, we should promote the optimization and upgrading of industrial structure, constantly improve the proportion of tertiary industry and actively develop modern service industry. Secondly, we should make full use of the coal and wind power in Ningdong Energy Chemical Base of Ningxia province. Thirdly, relying on exploiting and taking advantages of the abundant resources in $\mathrm{Gu}$ yuan city, such as rich coal, rock salts, limestone and other mineral resources, we should strive to develop $\mathrm{Gu}$ yuan Circular Economic Poverty-alleviation Demonstration Base of Salt and Chemical Engineering . Moreover, we should make use of Ningxia' s coal and natural gas to develop the coal chemical industry and natural gas chemical industry. Fourthly, we should exploit high value-added activated carbon and develop different kinds of top-class and high added value carbon products. Fifthly, we should work actively to develop top-quality cashmere products, extend industry chain and improve competitiveness of Ningxia cashmere products. Last but not the least, we should expand the grape cultivation areas of the superior wine-making in the east of Helan Mountain and promote the centralization and upgrading of the superior wine-making industry of Ningxia province. 


\section{B. Promoting the New Energy Industry of Photovoltaic and Wind Power}

First of all, we should take full advantages of the solar energy and wind power to propel the development and utilization of new energies.Moreover, we should evaluate the solar and wind energy resources and plan the layout and scale of electric field. Besides that, we should do more research in the core technology of solar energy industry and supported products of it and improve the proportion of Ningxia' $\mathrm{s}$ wind and electric equipments.

\section{Actively Promoting the Carbon Sinks in Agriculture}

Specializing in saving irrigation water, lowering investment in chemicals and standardizing high quality seeds cultivation, Ningxia should endeavor to reduce the reliance on high-carbon materials, decrease carbon emissions of crops, and convert the old-fashioned agricultural production mode to high-yield, high-quality, high-efficiency, safe and ecological agriculture one. Besides, we should increase the areas of forest and grassland, sparing no efforts to build a resource-saving, environment-friendly and efficient circulation agricultural system.

\section{D.Endeavouring to Construct a Low-Carbon City}

Rapid urban development is one of the primary reasons that caused high carbon emissions and the reason why we should develop low-carbon economy. It will take a long time for Ningxia to pursue urbanization. Only does Ningxia mobilize its affuent resources and select a right routine to develop can it become a significant platform leading the development of low-carbon economy.

\section{E. Promoting Energy Conservation and Emission Reduction and Developing Circular Economy \\ Under the double pressure of achieving economic development and environmental protection, Ningxia should develop cleaner production and circular economy, enhance energy conservation and emission reduction and eliminate outdated productivity. Only by following the rules of national "Twelfth Five-Year Plan", such as reducing unit GDP resource consumption and carbon emissions can Ningxia make great-leap-forward development and build a resource-saving and environment- friendly society. \\ F. Positively Cultivating Service Industry with Low-Carbon Technology}

We should optimize the environment of low-carbon service industry and promote the marketization of scientific and technological service industry for developing lowcarbon industries which is characterized by high technology,energy-saving and good prospect. In order to conquer those difficulties like short industry chain of the high energy consumption industries, poor management, low added value of products and weak market competitiveness of Ningxia province, the government should offer scientific and technological services and support to achieve economic transition.

\section{G. Striving to Develop Low-Carbon Industry of Tourism and Culture}

We should actively develop the industry of entertainment, information service, cultural originality and other low-carbon service industries, promoting the combination of low-carbon industry and traditional industry and upgrading industries. Therefore, Ningxia' s industrial structure will approach to the structure of low carbon economy and form the low-carbon enterprises and chains.

\section{H. Co-creating a Low-carbon Lifestyle}

While developing low carbon economy and building low-carbon society by relying on technological and institutional innovation, we should also update notions of all citizens in this city and call for the whole society to actively participate in the activities of co-creating low-energy, lowconsumption, low-spending and low-carbon life. Besides, everyone should establish the idea of living a low-carbon life and form a good habit of energy conservation and emission reduction, promoting the harmonious development between nature and humans.

\section{CONCLUSIONS}

In this paper, we conduct theoretical analysis and numerical simulation on the topic of the approaches and countermeasures of developing low carbon economy for the twelfth five-year plan of Ningxia Hui autonomous region. Ethnic people of Ningxia have made great achievements in economic and social development under the leadership of Chinese government these years. The comprehensive strength and abundant natural resources lay a sound foundation for developing low carbon economy of their "Twelfth- Five Year" plan. In order to implement the national strategic deployment and specific tasks in developing low carbon economy, during the period of the 'Twelfth Five-Year Plan', Ningxia Hui Autonomous Region put forward the idea of establishing ecological, green and low-carbon development. The numerical result illustrates the robustness and the feasibility of the proposed methodology which will be meaningful.

\section{Acknowledgment}

This paper aided financially by the Scientific Research Project of Northern University for Nationalities, "Study on the Pathway and Countermeasures of the "12th Five-year " Low Carbon Economy Development in Ningxia (No.2012Y008)". 
Research project of Nat ional Social Science Fund (An Ordinary project):A Research into the Change of Age Structure of Population and Economic Development in Western Region at New Period No.2012BRK023

\section{REFERENCE}

[1]Statistical Yearbookof Ningxia Province, Ningxia Statistical Bureau, 2011,pp213-218 